\title{
UP Philippine General Hospital Division of Endocrinology, Diabetes \& Metabolism \\ Consensus Recommendations for In-Patient Management of Diabetes Mellitus among Persons with COVID-19
}

\author{
Cecilia Jimeno, Ma. Cecille Anonuevo-Cruz, Angelique Bea Uy, Adrian Oscar Bacena, \\ Mark David Francisco, Angelique Love Tiglao-Gica, Racquel Bruno, Diane Grace Corpuz \\ Division of Endocrinology, Diabetes and Metabolism, University of the Philippines-Philippine General Hospital
}

\begin{abstract}
Diabetes mellitus (DM) is a known risk factor for morbidity and mortality among patients with COVID-19 based on recent studies. While there are many local and international guidelines on inpatient management of diabetes, the complicated pathology of the virus, the use of glucose-elevating drugs such as glucocorticoids, antivirals and even inotropes, and various other unique problems has made the management of in-hospital hyperglycemia among patients with COVID-19 much more difficult than in other infections. The objective of this guidance is to collate and integrate the best available evidence that has been published regarding in-patient management of diabetes among patients with COVID-19. A comprehensive review of literature was done and recommendations have been made through a consensus of expert endocrinologists from the University of the Philippines-Philippine General Hospital (UP-PGH) Division of Endocrinology, Diabetes and Metabolism. These recommendations are evolving as we continue to understand the pathology of the disease and how persons with diabetes are affected by this virus.
\end{abstract}

Key words: In-patient management, diabetes, COVID-19, SARS-COV-2

\section{INTRODUCTION}

The severe acute respiratory syndrome coronavirus 2 (SARS-COV-2) is a novel coronavirus that was first recognized in Wuhan, China in December 2019. Since then, it has spread quickly and is now considered a global pandemic. Despite the many researches that have been published, much remains unknown regarding SARSCoV-2 and its designated disease, COVID-19.

Diabetes mellitus (DM) is a known risk factor for severe illness among patients with COVID-19. In a retrospective cohort study of confirmed COVID-19 patients in China, diabetes was identified as the second most common comorbidity, found in $7.4 \%$ of patients. ${ }^{1}$ A meta-analysis of 12 studies also from China reported that diabetes was present in $10.3 \%$ of more than 2,000 patients with COVID-19, ${ }^{2}$ which was similar to their 2013 national prevalence of $10.9 \% .^{3}$ Diabetes was likewise a prognostic factor for ICU admission, acute respiratory distress syndrome (ARDS) (OR 2.34 [1.35-4.05]), and mortality (OR 2.85 [1.35-6.05].-6 Epidemiological studies of countries with high disease burden showed that the risk of dying from COVID-19 is up to $50 \%$ higher among persons with diabetes compared to those who do not have diabetes.
While there are many local and international guidelines on inpatient management of diabetes, the complicated pathology of the virus, the use of glucose-elevating drugs such as glucocorticoids, antivirals and even inotropes, and various other unique problems has made the management of in-hospital hyperglycemia among patients with COVID-19 much more difficult than in other infections. Coupled with these are the difficulties in feeding those who have COVID-19 due to the management of respiratory failure that involves putting the patient in a prone position.

The objective of this guidance is to collate and integrate the best available evidence that has been published regarding in-patient management of diabetes among patients with COVID-19. A comprehensive review of literature was done and recommendations have been made through a consensus of expert endocrinologists from the University of the Philippines-Philippine General Hospital (UP-PGH) Division of Endocrinology, Diabetes and Metabolism.

\section{Unique Problems of Diabetes Management among Patients with COVID-19}

It is complacent to think that COVID-19 is just another infection that necessarily triggers higher stress conditions and the release of catecholamines and glucocorticoids,
Corresponding author: Cecilia A. Jimeno, MD, FPCP, FPSEDM

Past President, Philippine Society of Endocrinology, Diabetes and Metabolism Professor, College of Medicine, Department of Pharmacology and Toxicology, University of the Philippines Manila

Clinical Professor, Division of Endocrinology, Diabetes and Metabolism,

University of the Philippines-Philippine General Hospital

Taft Avenue, Ermita 1000 Manila, Philippines

Tel. No.: +632-85264550

E-mail: cajimeno@up.edu.ph

ORCiD: https://orcid.org/0000-0002-7658 
leading to hyperglycemia and abnormal glucose variability. While it is true that the greater majority of those affected with SARS-COV-2 will have only minor illness and will likely have only mild perturbations of their blood sugar levels, it appears that there are emerging novel aspects of hyperglycemia among those with COVID-19.

One of these unique features is the observation of very high insulin requirements among those with a severe course of the infection, even among those who are not on glucocorticoids. We have observed this even in the cohorts of patients whom we have seen at the PGH, necessitating high doses of insulin given intravenously. According to a recent publication in the Lancet, it appears that the extent of insulin resistance in patients with COVID-19 and diabetes appears to be disproportionate compared with critical illness from other conditions. ${ }^{8}$

There are also reports of a greater incidence of diabetes emergencies among persons with diabetes and COVID-19. It is already established that the virus gains entry to cells through an endocrine pathway, the AngiotensinConverting-enzyme-2 (ACE2) receptor. Cellular damage can be caused by both acute and chronic hyperglycemia, as the former causes the up-regulation of ACE2 expression facilitating viral entry. Chronic hyperglycemia, on the other hand, causes reduced expression of ACE2 potentially through glycosylation, making the cells vulnerable to the cell-damaging effects of the virus. ACE2 is recognized to have anti-inflammatory and anti-oxidant functions. ${ }^{9}$ The pancreatic beta-cells are known to express the ACE2 receptors suggesting (although without yet direct human verification) that the COVID-19 infection can induce new-onset diabetes by beta-cell damage. This could potentially then cause insulin deficiency, explaining the observations of both the UK and Italian investigators of frequent cases of severe diabetic ketoacidosis (DKA) and even atypical ketosis among persons with Type 2 diabetes, at the time of hospital admission..$^{9-11}$

Finally, hypoglycemia (at least one episode of BG $<3.9 \mathrm{mmol} / \mathrm{L}$ ) has been noted in around $10.3 \%$ of patients with COVID-19 and diabetes in Wuhan, China. ${ }^{12}$ Some of the risk factors for hypoglycemia may include the development of acute renal failure, interruptions in feeding whenever patients are put on prone position as part of the management of respiratory distress, and the use of chloroquine or hydroxychloroquine which are known to cause hypoglycemia as a side effect. This underscores the importance of routinely monitoring the capillary blood glucose of patients started on these drugs. ${ }^{13}$ Hypoglycemia has been shown to mobilize pro-inflammatory monocytes and increase platelet reactivity, contributing to a higher cardiovascular mortality in patients with diabetes. ${ }^{14}$ These mechanisms may interact with chronic inflammation, increase coagulation activity, further impair immune response and with potential direct pancreatic damage by SARS-CoV-2, may explain the underlying pathophysiological mechanisms contributing to the increased morbidity and mortality of COVID-19 in people with diabetes. ${ }^{15}$

The satisfactory control of diabetes, with avoidance of both hyperglycemia and hypoglycemia is therefore critical in preventing morbidity and mortality among diabetics with COVID-19 infection.

\section{SPECIFIC RECOMMENDATIONS}

\section{What do we assess at the emergency room?}

- Routine point of care testing for blood sugar should be done for all patients with COVID-19 to rapidly identify new cases of diabetes and to assess blood sugar control; any random CBG $>140 \mathrm{mg} /$ dl $(>7.8 \mathrm{mmol} / \mathrm{L})$ should routinely be monitored within the next 24 hours.

- Urine or serum ketone determination, in all patients with known diabetes or those with admission glucose over $220 \mathrm{mg} / \mathrm{dl}$ (12 mmol/L), as COVID-19 infection causes ketosis or ketoacidosis, which may increase the length of hospital stay and mortality. ${ }^{16,17}$

- Identify obese patients because the interaction of diabetes and obesity increases the risk for severity of COVID-19.18

- Triage: Identify those with diabetic emergencies who need ICU admission

1.1 Recognition of Acute Hyperglycemic Emergencies: DKA or HHS should be considered among those with known or suspected diabetes presenting with:

- Nausea and vomiting, abdominal pain

- Signs and symptoms of dehydration, hypotension or shock

- Acid-smelling (alcohol) breath

- "Acidotic" breathing (tachypneic but with clear breath sounds)

- Altered consciousness or coma

- High blood sugar [CBG or RBS $\geq 250 \mathrm{mg} / \mathrm{dL}$ (13.9 mmol/L)]

- A history of Type $1 \mathrm{DM}$ or being on insulin

- Precipitant risk factors such as severe infection

1.2 General Plan of Management:

See Appendix A for Management of Adult Patients with DKA or HHS.

\section{What baseline laboratory tests should be done?}

Baseline laboratory tests to determine glycemic control such as HbA1c (if without anemia or with acceptable hemoglobin levels), fasting blood sugar or random blood sugar should be obtained. Point-of-care testing by obtaining the capillary blood glucose level should be done upon admission. Other diagnostic examinations to determine the presence of DM-related complications should be requested such as creatinine with estimated glomerular filtration rate, urinalysis with urine albumin, glucose and ketones and 12-lead ECG.

Some studies show development of ketosis and severe insulin resistance among patients with COVID-19 and diabetes, thus laboratory tests such as serum sodium, potassium, blood urea nitrogen, chloride and arterial blood gas are important and should be done, along with blood or urine ketones. Additionally, serum albumin, phosphorus and magnesium can be taken for complete nutritional assessment, as well as calcium to assess risk for arrhythmias. Coagulation profile may be warranted, 
since apart from COVID-19-related inflammatory processes, insulin resistance and Type 2 diabetes mellitus are associated with endothelial dysfunction, and enhanced platelet aggregation and activation. These abnormalities contribute to the development of a hypercoagulable prothrombotic state. ${ }^{6}$

\section{What should be the frequency of blood sugar monitoring?}

There is no reason to believe that the established guidelines and standard of care for the treatment of infections among patients with diabetes may not be extended to those who are diagnosed with COVID-19. In particular, the 2020 ADA Standards of Diabetes $\mathrm{Care}^{19}$ recommends the following schemes for monitoring of blood glucose:

a. In hospitalized patients with diabetes who are eating, glucose monitoring should be performed before meals and at bedtime;

b. In those not eating, glucose monitoring is advised every 4-6 hours.

c. More frequent blood glucose testing ranging from every $30 \mathrm{~min}$ to every 2 hours is the required standard for safe use of intravenous insulin.

Special consideration must be taken for patients who have blood glucose values that are $250-300 \mathrm{mg} /$ $\mathrm{dL}(>15 \mathrm{mmol} /)$; for those who are critically-ill in the intensive care unit, there may be a need to start an insulin drip using a standard protocol which would require hourly monitoring. Diabetes emergencies also need to be ruled out for these severely elevated values for which more dynamic drip protocols are needed (Section 5).

Once blood sugar is controlled and glycemic targets achieved, CBG monitoring may be adjusted accordingly.

Additionally, the Philippine Society of Endocrinology, Diabetes, and Metabolism (PSEDM), in their Position Statement published March 202020 recommends the following:

a. Patients who have stable vital signs may be allowed to take their own blood glucose test while being visually monitored by a nurse or physician.

b. When possible, the use of continuous glucose monitoring (CGM) is encouraged to help mitigate the exposure of healthcare workers to COVID-19 cases, provided regular calibration with the standard blood glucose testing is undertaken.

\section{What are the expected glycemic targets? ${ }^{20-22}$}

The general treatment goals for patients with diabetes are to address or prevent acute glycemic decompensation, prevent or delay the development of microvascular and macrovascular disease complications, avoid adverse events like hypoglycemia, decrease mortality, and provide a smooth transition to outpatient care.

The general target blood glucose levels for hospitalized patients is around 140 to $180 \mathrm{mg} / \mathrm{dl}$ (7.8 to $10 \mathrm{mmol} / \mathrm{l})$.
Blood glucose levels $>180 \mathrm{mg} / \mathrm{dl}(10 \mathrm{mmol} / \mathrm{l})$ may require an increase in insulin dose.

\section{When should we refer to an endocrinologist?}

5.1 When caring for hospitalized patients with diabetes and COVID-19 (suspected, probable or confirmed), we recommend ROUTINE referral to endocrinology service or a specialized diabetes or glucose management team whenever possible. ${ }^{19,20}$ This is especially true for moderate and severe cases of COVID-19 where the hyperglycemia is more likely.

5.2 Particularly, the following patients should be referred to the Endocrinology Service as soon as possible:

- $\quad$ Any person with Type 1 diabetes

- Known diabetes with poor blood sugar control $[\mathrm{HbA} 1 \mathrm{c} \geq 9 \%$ or BG values $200 \mathrm{mg} / \mathrm{dl}$ (11.1 mmol/l) and above]

- Newly-diagnosed diabetes

- Elderly with diabetes

- Known patient with diabetes on insulin therapy

- Pregnant women with diabetes (overt, gestational or pre-gestational diabetes)

- Known or suspected hyperglycemic or hypoglycemic emergencies.

- Known patients with diabetes with multiple comorbidities such as chronic kidney disease, heart failure or previous acute coronary syndrome, stroke, peripheral arterial disease/prior amputation.

\section{Management of Hyperglycemia and Associated Metabolic Conditions ${ }^{23,24}$}

Hydration and nutrition therapy are integral components of patient care, both for critical and noncritical COVID-19 patients.

6.1 Fluids / Hydration (for those allowed oral intake with no prescribed limitations):

- Approximately 3 liters of fluid intake per day

- Optimal fluids: clear liquids with calories and protein, oral rehydration solutions or low glucose sports drinks

- Fluid limitation and caution on hydration is advised for those with Acute Respiratory Distress Syndrome (ARDS)/ Severe Acute Respiratory Infection (SARI)/ Heart Failure/ Acute Kidney Injury or Chronic Kidney Disease.

6.2 Medical Nutrition Therapy: Equal caloric distribution per meal throughout the day is recommended with the following guidance:

- Total Caloric Requirement: Generally computed as $25-30 \mathrm{kcal} / \mathrm{kg}$ per day with specific recommendations for the critically and those at risk of refeeding syndrome (Appendix B)

- Protein: $\geq 1$ gram/kg per day 
- The nutritional needs of patients should be optimized through a multi-disciplinary team of clinical nutritionists, dieticians and specialized physicians.

See Appendix B1 and B2 for Guidance on Nutrition Therapy for Adults with confirmed or suspected SARS-COV-2 Infection (PhilSPEN and ESPEN Guidelines)

6.3 Should oral antidiabetic agents be continued during admission? 8,25

6.3.1 Most anti-diabetic agents may need to be discontinued during admission in favor of insulin, unless the blood sugar control is good and the COVID-19 infection is mild. This is especially true for metformin, SGLT-2 inhibitors and sulfonylureas/glinides, and probably the only exception might be DPP4-inhibitors. Take note that hydroxychloroquine (HCQ) is known to cause hypoglycemia among those on oral hypoglycemic agents or insulin, and in fact is licensed as an anti-diabetic agent in India.

6.3.1.1 Metformin may cause lactic acidosis in patients who are dehydrated. Those with severe COVID are also prone to acute kidney injury, increasing the risk for metformin-associated lactic acidosis (MALA).

6.3.1.2 Sulfonylureas such as glibenclamide, gliclazide, glimepiride and glipizide should generally be discontinued for most patients during hospitalization, because of the risk for hypoglycemia, especially when combined with insulin and hydroxychloroquine.

6.3.1.3 Sodium-glucose-co-transporter 2 (SGLT-2) inhibitors, e.g., canagliflozin, dapagliflozin and empagliflozin, may cause dehydration and predispose to acute kidney injury, and may also precipitate diabetic ketoacidosis during the hospitalization.

6.3.1.4 Glucagon-like peptide-1 receptor agonists (GLP-1 RA) including exenatide (and exenatide extended release), liraglutide, lixisenatide and semaglutide should be used with caution and are generally discontinued in the seriously ill. These agents increase risk of nausea and vomiting, which may induce dehydration.

6.3.1.5 Dipeptidyl peptidase-4 inhibitors (DPP-4i) include alogliptin, linagliptin, saxagliptin, sitagliptin and tenelegliptin. There is some concern about these drugs because the DPP-4 enzyme has been identified in cell studies as a receptor for the human coronavirus-Erasmus Medical
Center (hCoV-EMC), the virus that causes Middle East respiratory syndrome (MERS). ${ }^{26}$ It is still unknown whether these mechanisms apply to COVID-19 and whether treatment with DPP4inhibitors could potentially influence the course of the infection. However, if these mechanisms are translatable to SARS-CoV-2, then the use of these agents could potentially reduce DPP4 concentrations and thus, present as opportunities for its treatment. ${ }^{27}$ These drugs are also generally safe and well tolerated, and can be continued even during the hospitalization.

\section{How should insulin be administered? ${ }^{28}$}

7.1 Administration of insulin using prolonged "Sliding Scale" alone is NOT recommended as it is reactive to a pre-existing hyperglycemia and if improperly timed may lead to hypoglycemia. These oscillations are termed "glycemic variability." Both hyper- and hypoglycemia have been known to be pro-inflammatory and thus, may aggravate the already overactive inflammatory response in COVID-19. Coupled with this is the fact that large glycemic variability is per se predictive of high ICU mortality. ${ }^{29}$

7.2 Generally, the ideal regimen should be a basalbolus regimen, with a long acting basal insulin analogue given once a day or NPH insulin given once to twice a day, plus rapid-acting or regular insulin given pre-meals.

In starting insulin, calculate the today daily dose as follows:

- Elderly (aged 70 years and above) and/or glomerular filtration rates less than $60 \mathrm{ml} /$ min: 0.2 to $0.3 \mathrm{U} / \mathrm{kg}$ of body weight per day

- Adults with blood glucose concentration 7.8$11.1 \mathrm{mmol} / \mathrm{L}$. (140-200 mg/dL): $0.4 \mathrm{U} / \mathrm{kg}$ of body weight per day

- Adults with blood glucose concentration 11.2-22.2 (201-400 mg/dL): $0.5 \mathrm{U} / \mathrm{kg}$ of body weight per day

Distribute the total calculated dose as approximately $50 \%$ basal insulin and $50 \%$ bolus insulin divided into three pre-meal doses. Adjust insulin dose(s) according to the result of bedside blood glucose measurements.

7.3 Generally, for patients who are on insulin as their previous management, basal insulin $(\mathrm{NPH}$ insulin 2x/day or Basal insulin analogues: Glargine U100, Detemir) should be continued and adjusted accordingly, adding on prandial insulin coverage depending on how the patient will be fed.

7.4 For severe cases of COVID-19. An expert opinion from European authors has stated that there is a, ".... liberal indication for early intravenous insulin therapy in severe courses 
(ARDS, hyperinflammation) for exact titration, avoiding variable subcutaneous resorption, and commonly seen very high insulin consumption" ${ }^{\prime 8}$ (Section 7.1).

\section{Other Medications}

8.1 Statins: There is also some concern for the use of statins, as its use has been associated with the up-regulation of the ACE2 receptor levels, and in fact this is the mechanism that has been used to explain the pleiotropic anti-inflammatory effect of this drug. Again, this upregulation may facilitate the entry of the virus. However, most of the experts across the world have recommended that statins should be continued among patients with diabetes and COVID-19 not only because of its long term benefit for cardiovascular disease reduction in established diabetes, but also because mechanistically its discontinuation may tip the balance towards a cytokine storm by causing rebound increases in the levels of IL- 6 and IL-1. ${ }^{8}$

8.2 Anti-hypertensives: The fact that the SARS-COV2 uses the ACE-2 receptor as the entry point inside the cells has created some concern over the use of ACE-inhibitors and Angiotensin Receptor Blockers (ARBs). However, there appears to be no definite evidence that the use of these drugs worsens the outcome for those who use it. This is the position of most expert groups including the European Society of Cardiology and the Heart Failure Society of America, American College of Cardiology, American Heart Association, and even the local Philippine Society of Hypertension. These organizations strongly recommend continuation of treatment with ACE inhibitors and angiotensin 2 receptor blockers unless there are contraindications such as shock or acute kidney injury. ${ }^{30,31}$

8.3 Anti-platelets: Low dose aspirin or clopidogrel is typically given to persons with diabetes who are at high risk of major adverse cardiovascular events. $^{32,33}$ It is therefore reasonable that among those who are taking these drugs as maintenance medications, they should be continued during the hospitalization unless there are specific contraindications to their use especially among those with severe COVID-19 infections.

\section{Special Circumstances}

9.1 Identifying the critically ill patient (who is not diagnosed to be in Hyperglycemic Emergency) who may require an insulin drip protocol

The following are the indications for those who may require an Insulin Drip:

- $\quad$ CBG $\geq 180 \mathrm{mg} / \mathrm{dl}$ on 2 consecutive CBG, and

- On (prolonged) NPO or on Total Parenteral Nutrition (TPN), or

- Severe cases of COVID-19 (SARI) or critically ill with shock and on inotropes not diagnosed as DKA and HHS
The Yale insulin infusion protocol was modified because of the revision of the blood glucose targets to a higher range of $140-180 \mathrm{mg} / \mathrm{dl}$ among critically ill patients. These changes were made due to findings of previous RCTs with blood glucose levels of $80 \quad-100 \quad \mathrm{mg} /$ dl showed increased mortality rate and increased risk of hypoglycemia. The modified Yale protocol was validated among patients admitted to ICU units in UP-PGH and has been in use since 2009. It is considered to be effective with shorter median time to normoglycemia (70-180 mg/dl) (4 vs 12 hours) and greater mean percentage of total measurements blood glucose level within normoglycemic range (BG 70$180 \mathrm{mg} / \mathrm{dl})(73.84 \% \pm 17.68 \%$ vs $51.74 \% \pm 25.03 \%$, $\mathrm{p}<0.0001)$ as compared to historical control group. It is also considered to be safe with rare episodes of hypoglycemia and with no episodes of severe hypoglycemia. ${ }^{34,35}$

See Appendix C for the PGH Modified Yale Insulin infusion protocol.

\subsection{Glucocorticoid Use in COVID-19}

Glucocorticoids (GCs) have a potent antiinflammatory effect and antifibrotic properties, thus, their use was explored for moderate to severe COVID-19 infections. However, there are no published randomized controlled trials to support its use due to lack of effectiveness and possible harm by delaying viral clearance and risk of concomitant infections. A conditional recommendation of use may be made for patients with concomitant asthma exacerbation or COPD or sepsis/septic shock refractory to vasopressors and fluids due to the possibility of critical illnessrelated corticosteroid insufficiency (CIRCI). ${ }^{13,36-38}$

9.2.1 The development of insulin resistance manifests mainly with postprandial hyperglycemia, and varies depending on the type of steroid used. The use of methylprednisolone has been proposed for severe COVID-19 infection. ${ }^{32}$ It is classified as an intermediate-acting GCs, with a peak of action 4-6 $\mathrm{h}$ following administration. Its effect on glucose levels is mainly during the afternoon and night without much effect on fasting glucose when administered in a single dose but glucocorticoids cause persistent hyperglycemia when administered in divided doses.

9.2.2 Management of hyperglycemia among those being given glucocorticoids ${ }^{39}$

9.2.2.1 Capillary glucose monitoring should commence from the start of steroid treatment. Hyperglycemia develops within 1-2 days of initiation of steroid therapy. 
- In nondiabetic patients who maintain glucose levels $<140 \mathrm{mg} / \mathrm{dL}$ without insulin requirements for $24-48 \mathrm{~h}$, glycemic monitoring can be discontinued.

- In patients with glucose levels $>140 \mathrm{mg} / \mathrm{dL}$ with persistent insulin requirements, a basal/ bolus subcutaneous insulin scheme may be started (Section 6.5).

9.2.2.2 Among those who require insulin, steroid-induced hyperglycemia will typically have a much higher prandial insulin requirement compared those who are not on steroids.

9.2.2.3 In patients with severe and/or persistent hyperglycemia despite a subcutaneous regimen, insulin by infusion pump should be started (Appendix C).

\section{CONCLUSIONS}

These recommendations are meant to be guides in managing patients with diabetes and COVID-19 infection. They are not meant to replace sound judgment and individualized therapy according to the specific patient circumstances. These guidelines are also a work in progress and feedback from other experts, scientists and clinicians are appreciated so that this manuscript can continue to be revised and improved.

Finally, these recommendations are evolving as we continue to understand the pathology of the disease and how persons with diabetes are affected by this virus.

\section{Acknowledgments}

The authors thank the following: Faculty of the UP-PGH Division of Endocrinology: Emeritus Professor Mary Anne VA LimAbrahan, Laura T. Acampado (Division Chief), Frances Lina Lantion-Ang (Training Officer), Elizabeth Paz-Pacheco (Immediate past Chief), Myrna Buenaluz-Sedurante, Gabriel V. Jasul, Cecilia A. Jimeno, Iris Thiele Isip-Tan, Nemencio A. Nicodemus, Jr, Ma. Cecille Anonuevo-Cruz, Mia A. Fojas, Mark Anthony S. Sandoval, Patricia Maningat-Goco, Tom Edward Lo, Ralph Jason Li.

Fellows-in-training: Adrian Oscar Bacena, Racquel Bruno, Diane Grace Corpuz, Mark David Francicso, Angelique Love TiglaoGica, Angelique Bea Uy, Anna Elvira Arcellana, Aura Bree Dayo-Lacdao, Hydelene Dominguez, Ma. Belen Pilit-Hizon, Jen Jasa-Ngalob, Harold Henrison Chiu, Edrome Hernandez, Franz Michael Magnaye, Carmegie Saliba, Jereel Aron Sahagun, Ma. Elena Saquilayan, Jim Paulo Sarsagat.

\section{Statement of Authorship}

All authors certified fulfillment of ICMJE authorship criteria.

\section{Author Disclosure}

The authors declared no conflict of interest.

\section{Funding Source}

None.

\section{References}

1. Guan WJ, Ni ZY, Hu Y, et al. Clinical characteristics of coronavirus disease 2019 in China. N Engl J Med. 2020;382(18):1708-20. PMID: 32109013. PMCID: PMC7092819. https://doi.org/10.1056/ NEJMoa2002032.

2. Fadini GP, Morieri ML, Longato E, Avogaro A. Prevalence and impact of diabetes among people infected with SARS-CoV-2. Endocrinol Invest. 2020. PMID: 32222956. PMCID: PMC7103097. https://doi.org/10.1007/s40618-020-01236-2.

3. $\mathrm{Xu} \mathrm{Y,} \mathrm{Wang} \mathrm{L,} \mathrm{He} \mathrm{J,} \mathrm{et} \mathrm{al.} \mathrm{Prevalence} \mathrm{and} \mathrm{control} \mathrm{of} \mathrm{diabetes}$ in Chinese adults. JAMA. 2013;310(9):948-59. PMID: 24002281. https://doi.org/10.1001/jama.2013.168118.

4. Wang $\mathrm{D}, \mathrm{Hu} \mathrm{B}, \mathrm{Hu} \mathrm{C}$, et al. Clinical characteristics of 138 hospitalized patients with 2019 novel coronavirus-infected pneumonia in Wuhan, China. JAMA. 2020;323(11):1061-9. PMID: 32031570. PMCID: PMC7042881. https://doi.org/10.1001/jama.2020.1585.

5. Wu Z, McGoogan JM. Characteristics of and important lessons from the coronavirus disease 2019 (COVID-19) outbreak in China. JAMA. 2020;323(13):1239-42. PMID: 32091533. https://doi. org/10.1001/jama.2020.2648.

6. Zhou $\mathrm{F}, \mathrm{Yu} \mathrm{T}, \mathrm{Du} \mathrm{R}$, et al. Clinical course and risk factors for mortality of adult inpatients with COVID-19 in Wuhan, China: A retrospective cohort study. Lancet. 2020;395(10229):1054-62. PMID: 32171076. https://doi.org/10.1016/S0140-6736(20)30566-3.

7. Remuzzi A, Remuzzi G. COVID-19 and Italy: What next? Lancet. 2020;395(10231):1225-8. PMID: 32178769. PMCID: PMC7102589. https://doi.org/10.1016/S0140-6736(20)30627-9.

8. Bornstein SR, Rubino F, Khunti K, et al. Practical recommendations for the management of diabetes in patients with COVID-19. Lancet Diabetes Endocrinol [Internet]. 2020;8587(20):1-5. Available from https://linkinghub.elsevier.com/retrieve/pii/S2213858720301522.

9. Bindom SM, Lazartigues E. The sweeter side of ACE2: Physiological evidence for a role in diabetes. Mol Cell Endocrinol. 2009;302(2):193-202. PMID: 18948167. PMCID: PMC2676688. https://doi.org/10.1016/j.mce.2008.09.020.

10. Roca-Ho H, Riera M, Palau V, Pascual J, Soler MJ. Characterization of ACE and ACE2 expression within different organs of the NOD mouse. Int J Mol Sci. 2017;18(3). pii:E563. PMID: 28273875 PMCID: PMC5372579. https://doi.org/10.3390/ijms18030563.

11. Yang JK, Lin SS, Ji XJ, Guo LM. Binding of SARS coronavirus to its receptor damages islets and causes acute diabetes. Acta Diabetol. 2010;47(3):193-9. PMID: 19333547. PMCID: PMC7088164. https://doi.org/10.1007/s00592-009-0109-4.

12. Zhou J, Tan J. Diabetes patients with COVID-19 need better blood glucose management in Wuhan, China. Metab Clin Exp. 2020;107:154216. PMID: 32220612. PMCID: PMC7102634. https://doi.org/10.1016/j.metabol.2020.154216.

13. Sanders JM, Monogue ML, Jodlowski TZ, Cutrell JB. Pharmacologic treatments for coronavirus disease 2019 (COVID-19): A review. JAMA. 2020. PMID: 32282022. https://doi.org/10.1001/jama.2020.6019.

14. Iqbal A, Prince LR, Novodvorsky P, et al. Effect of hypoglycemia on inflammatory responses and the response to low-dose endotoxemia in humans. J Clin Endocrinol Metab. 2019;104(4):1187-99. PMID: 30252067. PMCID: PMC6391720. https://doi.org/10.1210/jc.2018-01168.

15. Hussain A, Bhowmik B, do Vale Moreira NC. COVID-19 and diabetes: Knowledge in progress. Diabetes Res Clin Pract. 2020;162:108142. PMID: 32278764. PMCID: PMC7144611. https://doi. org/10.1016/j.diabres.2020.108142.

16. Diabetes UK. COncise adVice on Inpatient Diabetes (COVID: Diabetes): FRONT DOOR GUIDANCE. 2020. Available from https:// www.diabetes.org.uk/resources-s3/public/2020-04/COvID_Front_ Door v1.0.pdf.

17. Li J, Wang X, Chen J, Zuo X, Zhang H, Deng A. COVID-19 infection may cause ketosis and ketoacidosis. Diabetes Obes Metab. 2020. PMID: 32314455. https://doi.org/10.1111/dom.14057.

18. Simonnet A, Chetboun M, Poissy J, et al. High prevalence of obesity in severe acute respiratory syndrome coronavirus-2 (SARS-CoV-2) requiring invasive mechanical ventilation. Obesity (Silver Spring). 2020. PMID: 32271993. https://doi.org/10.1002/oby.22831.

19. American Diabetes Association. 15. Diabetes Care in the Hospital: Standards of Medical Care in Diabetes-2020. Diabetes Care. 2020;43(Suppl 1):S193-202. PMID: 31862758. https://doi.org/10.2337/ dc20-S015.

20. Philippine Society of Endocrinology Diabetes and Metabolism. Position Statement on COVID-19 Infection and Diabetes. J ASEAN Fed Endocr Soc. 2020. 2020;35(1):52-4. https://doi.org/10.15605/ jafes.035.01.02

21. International Diabetes Federation. COVID-19 outbreak: Guidance for people with diabetes. 2020. Available from https://www.idf.org/ our-network/regions-members/europe/europe-news/196-informationon-corona-virus-disease-2019-covid-19-outbreak-and-guidance-forpeople-with-diabetes.html.

22. NICE-SUGAR Study Investigators, Finfer S, Bellomo R, Blair D, et al. Intensive versus conventional glucose control in critically 
ill patients. N Engl J Med. 2009;360(13):1283-97. PMID: 19318384 https://doi.org/10.1056/NEJMoa0810625.

23. Barazzoni R, Bischoff SC, Breda J, et al. ESPEN expert statements and practical guidance for nutritional management of individuals with SARS-CoV-2 infection. Clin Nutr. 2020. pii: S0261-5614(20)30140-0. PMID: 32305181. PMCID: PMC7138149. https://doi.org/10.1016/ j.clnu.2020.03.022.

24. PhilSPEN. Guidance for Nutrition Therapy of Adults with Confirmed or Suspected COVID-19 [Internet]. Vol. 47;2020. Available from https://philspen.org/philspen-covid-19-update-algorithms-formanaging-nutritional-issues-among-patients-with-covid-19/.

25. Pal $R$, Bhadada SK. Should anti-diabetic medications be reconsidered amid COVID-19 pandemic? Diabetes Res Clin Pract. 2020;163(108146). PMID: 32283128. PMCID: PMC7151403. https://doi. org/10.1016/j.diabres.2020.108146.

26. Raj VS, Mou H, Smits SL, et al. Dipeptidyl peptidase 4 is a functional receptor for the emerging human coronavirus-EMC. Nature. 2013;495(7440):251-4. PMID: 23486063. PMCID: PMC7095326. https://doi.org/10.1038/nature12005.

27. Iacobellis G. COVID-19 and diabetes: Can DPP4 inhibition play a role? Diabetes Res Clin Pract. 2020;162:108125. PMID: 32224164 https://doi.org/10.1016/j.diabres.2020.108125

28. Umpierrez GE, Hellman R, Korytkowski MT, et al. Management of hyperglycemia in hospitalized patients in non-critical care setting: An endocrine society clinical practice guideline. J Clin Endocrinol Metab. 2012;97(1):16-38. PMID: 22223765. https://doi.org/10.1210/jc.2011-2098.

29. Chao WC, Tseng CH, Wu CL, Shih SJ, Yi CY, Chan MC. Higher glycemic variability within the first day of ICU admission is associated with increased 30-day mortality in ICU patients with sepsis. Ann Intensive Care. 2020;10(1):17. PMID: 32034567. PMCID: PMC7007493. https://doi.org/10.1186/s13613-020-0635-3.

30. American College of Cardiology. HFSA/ACC/AHA Statement Addresses Concerns Re: Using RAAS Antagonists in COVID-19. 2020. Available from https://www.acc.org/latest-in-cardiology/ articles/2020/03/17/08/59/hfsa-acc-aha-statement-addresses-concernsre-using-raas-antagonists-in-covid-19.

31. de Simone G. Position Statement of the ESC Council on Hypertension on ACE-inhibitors and angiotensin receptor blockers. European Society of Cardiology. 2020. Available from https://www.escardio.org/ Councils/Council-on-Hypertension-(CHT)/News/position-statementof-the-esc-council-on-hypertension-on-ace-inhibitors-and-ang.
32. Casado-Arroyo R. Aspirin and diabetes mellitus in primary prevention: The endless conundrum. Ann Transl Med. 2018:6(11):218. PMID: 30023381. PMCID: PMC6035968. https://doi.org/10.21037/ atm.2018.03.26.

33. American Diabetes Association 10. Cardiovascular Disease and Risk Management: Standards of Medical Care in Diabetes-2020. Diabetes Care. 2020;43(Suppl 1):S111-34. PMID: 31862753. https://doi org/10.2337/dc20-S010.

34. Josol C, Cardino M, Jimeno C, Isip-Tan I. Efficacy and safety of the UPPGH endocrine insulin infusion protocol in controlling hyperglycemia in UP-PGH Medical Intensive Care Unit and Central Intensive Care Unit. Unpublished. 2009.

35. Ngalob Q, Jimeno C, Isip-Tan IT. Evaluation of effectiveness and safety of an ICU insulin infusion protocol. J ASEAN Fed Endocr Soc. 2014;29(1):33-41. https://doi.org/10.15605/jafes.029.02.05

36. Zhang W, Zhao Y, Zhang F, et al. The use of anti-inflammatory drugs in the treatment of people with severe coronavirus disease 2019 (COVID-19): The perspectives of clinical immunologists from China. Clin Immunol. 2020:214:108393. PMID: 32222466. PMCID: PMC7102614. https://doi.org/10.1016/j.clim.2020.108393.

37. World Health Organization. WHO Clinical management of severe acute respiratory infection (SARI) when COVID-19 disease is suspected [Internet]. World Health Organization. 2020. Available from https://www.who.int/publications-detail/clinical-managementof-severe-acute-respiratory-infection-when-novel-coronavirus-(ncov)infection-is-suspected.

38. Philippine Society of Allergy Asthma and Immunology. A review of immunomodulators as therapeutic interventions for moderate to severe COVID-19 infections [Internet]. Unpublished. 2020. Available from https://pps.org.ph/wp-content/uploads/2020/04/LOGO-PSAAICOVID-19-Immunomodulator-Review-4-22-2020-DBA1.pdf.

39. Tamez-Pérez HE. Steroid hyperglycemia: Prevalence, early detection and therapeutic recommendations: A narrative review. World J Diabetes. 2015;6(8):1073-81. PMID: 26240704. PMCID: PMC4515447. https://doi.org/10.4239/wjd.v6.i8.1073.

40. Kitabchi AE, Umpierrez GE, Murphy MB, Kreisberg RA. Hyperglycemic crises in adult patients with diabetes: A consensus statement from the American Diabetes Association. Diabetes Care. 2006;32(7):1335-43. PMID: 19564476. PMCID: PMC2699725. https://doi.org/10.2337/dc09-9032.

Authors are required to accomplish, sign and submit scanned copies of the JAFES Author Form consisting of: (1) Authorship Certification, that authors contributed substantially to the work, that the manuscript has been read and approved by all authors, and that the requirements for authorship have been met by each author (2) the Author Declaration, that the article represents original material that is not being considered for publication or has not been published or accepted for publication elsewhere, that the article does not infringe or violate any copyrights or intellectual property rights, and that no references have been made to predatory/ suspected predatory journals; (3) the Author Contribution Disclosure, which lists the specific contributions of authors; and (4) the Author Publishing Agreement which retains author copyright, grants publishing and distribution rights to JAFES, and allows JAFES to apply and enforce an Attribution-Non-Commercial Creative Commons user license. Authors are also required to accomplish, sign, and submit the signed ICMJE form for Disclosure of Potential Conflicts of Interest. For original articles, authors are required to submit a scanned copy of the Ethics Review Approval of their research as well as registration in trial registries as appropriate. For manuscripts reporting data from studies involving animals, authors are required to submit a scanned copy of the Institutional Animal Care and Use Committee approval. For Case Reports or Series, and Images in Endocrinology, consent forms, are required for the publication of information about patients; otherwise, appropriate ethical clearance has been obtained from the institutional review board. Articles and any other material published in the JAFES represent the work of the author(s) and should not be construed to reflect the opinions of the Editors or the Publisher.

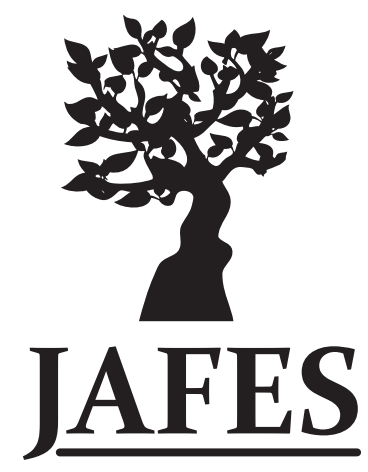

Experience the new JAFES. Visit us at www.ASEAN-endocrinejournal.org. 


\section{APPENDICES}

Appendix A. Protocol for Management of Adult Patients with Diabetic Ketoacidosis or Hyperglycemic Hyperosmolar State ${ }^{40}$

Complete initial evaluation. Check capillary glucose and serum/urine ketones to confirm hyperglycemia and ketonemia/ketonuria. Obtain blood for metabolic profile. Start IV fluids: $1.0 \mathrm{~L}$ of $0.9 \% \mathrm{NaCl}$ per hour. ${ }^{\dagger}$

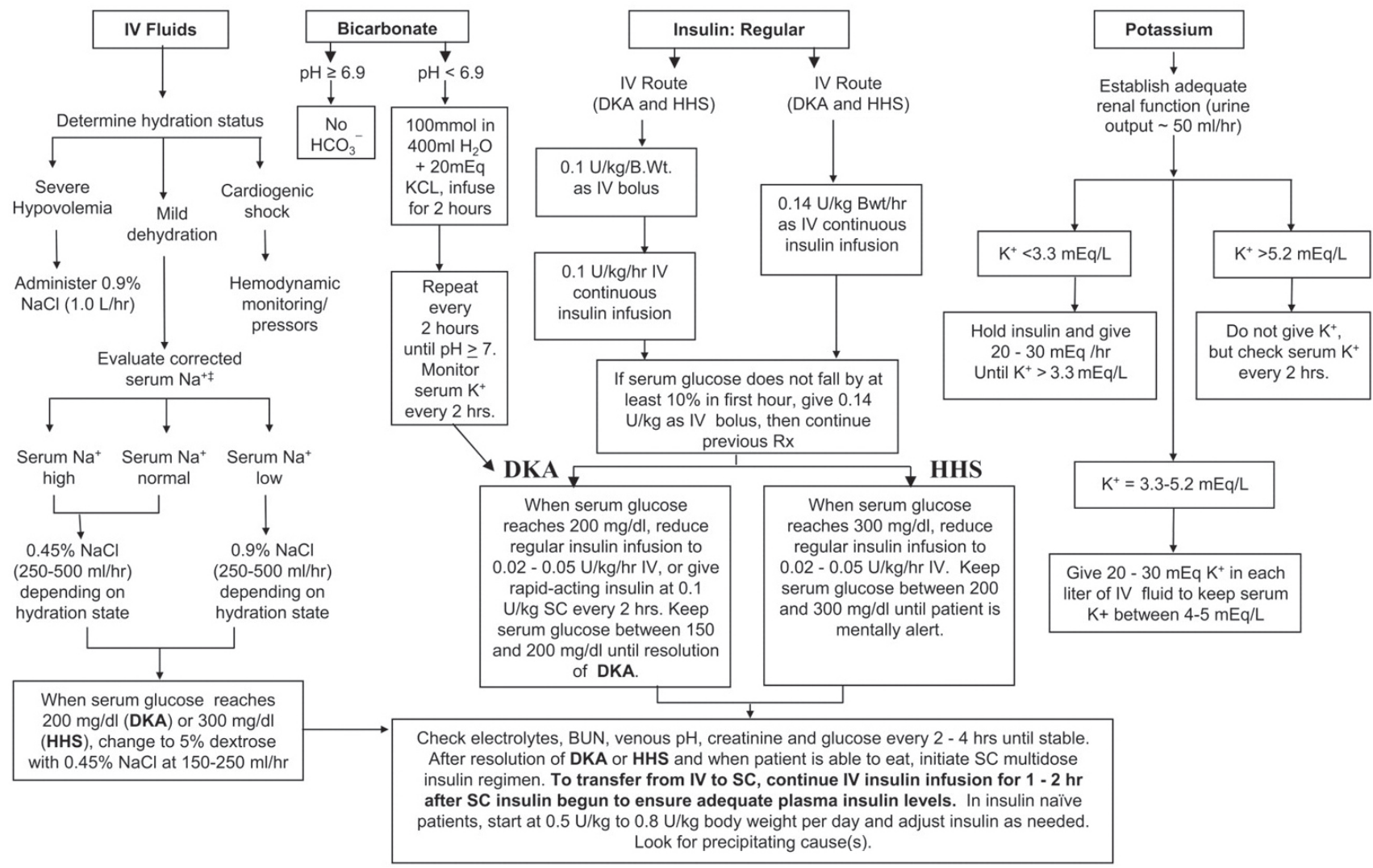

Protocol for management of adult patients with DKA or HHS. DKA diagnostic criteria: blood glucose $250 \mathrm{mg} / \mathrm{dl}$, arterial $\mathrm{pH} 7.3$, bicarbonate $15 \mathrm{mEq} / \mathrm{l}$, and moderate ketonuria or ketonemia. HHS diagnostic criteria: serum glucose $>600 \mathrm{mg} / \mathrm{dl}$, arterial $\mathrm{pH}>7.3$, serum bicarbonate $>15 \mathrm{mEq} / \mathrm{l}$, and minimal ketonuria and ketonemia. $† 15-20 \mathrm{ml} / \mathrm{kg} / \mathrm{h}$; $\ddagger$ serum Na should be corrected for hyperglycemia (for each $100 \mathrm{mg} / \mathrm{dl}$ glucose $100 \mathrm{mg} / \mathrm{dl}$, add $1.6 \mathrm{mEq}$ to sodium value for corrected serum value). (Adapted from ref. 13.) Bwt, body weight; IV, intravenous; SC, subcutaneous.

${ }^{*}$ Reproduced with permission from Dr. Guillermo Umpierrez, second author of the paper, as Dr. Abbas Kitabchi is already deceased. 
Appendix B.1. Philippine Society for Parenteral and Enteral Nutrition Guidance for Nutrition Therapy ${ }^{24}$

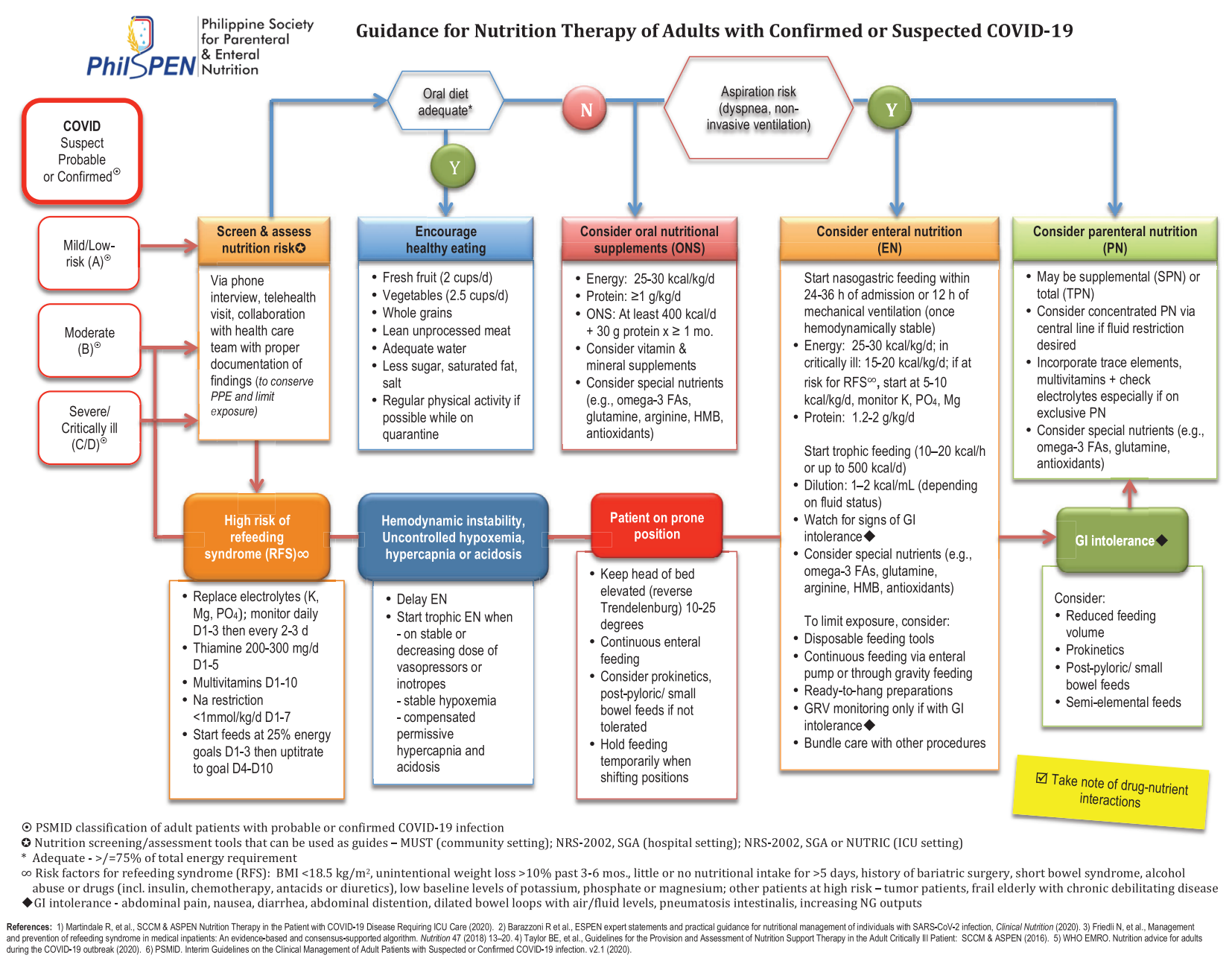

* Printed with permission from the primary author Joy Arabelle Castillo-Fontanilla,MD and from the president of PhilSociety of Parenteral and Enteral Nutrition (PhilSPEN) Jesus Fernando B. Inciong, MD, MSc. 
Appendix B.2. European Society of Parenteral and Enteral Nutrition Practical Guidance for Nutritional Management of Individuals with SARS-CoV-2 Infection (Adapted) ${ }^{23}$

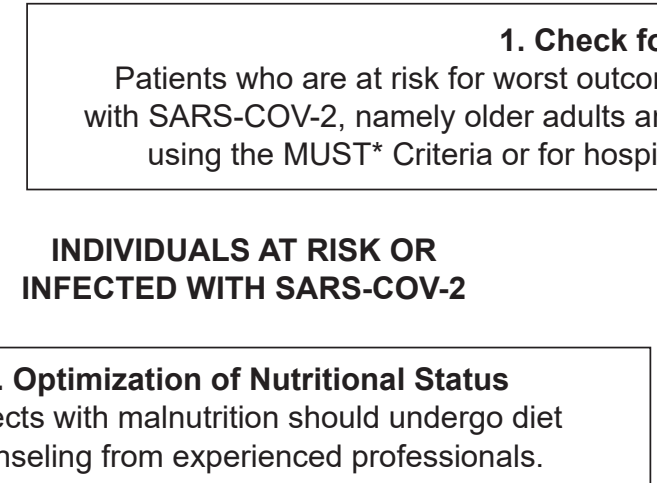

3. Supplementation with Vitamins and Minerals

Subjects with malnutrition should

ensure supplementation with vitamin A, vitamin $\mathrm{D}$ and other micronutrients.

\section{Regular Physical Activity}

Patients in quarantine should continue regular physical activity while taking precautions.

\section{Oral Nutrition Supplements (ONS)}

ONS should be used whenever possible to meet patient's needs, when dietary counseling and food fortification are not sufficient to increase dietary intake and reach nutrition goals.

\section{Enteral Nutrition (EN)}

In patients, whose nutritional requirements cannot be met orally, EN should be administered.

Parenteral nutrition (PN) should be considered when EN is not indicated or insufficient.
7. Medical Nutrition in Non-Intubated ICU Patients If the energy target is not reached with an oral diet, ONS should be considered first and then EN treatment. If there are limitations for the enteral route it could be advised to prescribe peripheral $\mathrm{PN}$ in the population not reaching energy-protein target by oral or enteral nutrition.

\section{Medical Nutrition in Intubated ICU Patients I}

EN should be started through a nasogastric tube; post-pyloric feeding should be performed in patients with gastric intolerance after prokinetic treatment or in patients at high-risk of aspiration.

\section{Medical Nutrition in Intubated ICU Patients II}

In ICU patients who do not tolerate full dose EN during the first week in the ICU, initiating parenteral nutrition

(PN) should be weighed on a case-to-case basis.

\section{Nutrition in ICU Patients With Dysphagia}

Texture-adapted food can be considered after extubation. If swallowing is proven unsafe, EN should be administered.

Nutritional management in individuals at risk for severe COVID-19, in subjects suffering from COVID-19, and in COVID-19 ICU patients requiring ventilation. For details, see text.

* MUST Criteria: is a five-step screening tool to identify adults who are malnourished, at risk of malnutrition (undernutrition), or obese. It can be downloaded for free at this website: www.bapen.org.uk

** NRS-2002 is a method endorsed by the ESPEN, to detect the presence of undernutrition and the risk of developing undernutrition in the hospital setting It contains the nutritional components of MUST, and in addition, a grading of severity of disease as a reflection of increased nutritional requirement. 


\section{Appendix C. PGH Modified Yale Protocol for Insulin Infusion ${ }^{35}$}

1. INSULIN INFUSION: Mix 1 unit Human Regular Insulin per 1 cc $0.9 \% \mathrm{NaCl}$. Administer in infusion pump (in increments of 1 unit/h).

2. PRIMING: Flush $50 \mathrm{cC}$ of infusion through all IV tubings before infusion begins (to saturate the insulin binding sites in the tubing).

3. THRESHOLD: Start IV insulin if BG is $>\mathbf{1 8 0} \mathbf{~ m g} / \mathbf{d l}$.

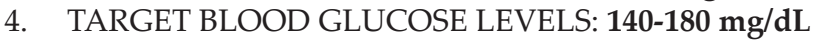

5. BOLUS \& INITIAL INSULIN INFUSION RATE: If initial BG $>180 \mathrm{mg} / \mathrm{dl}$ but $<300 \mathrm{mg} / \mathrm{dl}$, divide by 100 , then round to the nearest 1 unit for initial drip rate, (don't give IV bolus insulin). If initial BG is $\geq 300 \mathrm{mg} / \mathrm{dl}$, divide by 100 for bolus and initial drip rate.

\section{BLOOD GLUCOSE MONITORING}

1. Check blood glucose hourly until stable (3 consecutive values within target range). In hypotensive patients, capillary blood glucose (i.e., fingersticks) may be inaccurate and obtaining blood sample from an indwelling vascular catheter may be preferable.

2. Then check blood glucose q 2 hours; once stable $x$ 12-24 hrs. Blood glucose checks can then be spaced to q 4 hrs. IF:

a. no significant change in clinical condition AND

b. no significant change in nutritional intake

3. If any of the following occur, consider the temporary resumption of hourly blood glucose monitoring, until blood glucose is again stable (2-3 consecutive BG values within target range):

a. any change in insulin infusion rate (i.e., blood glucose out of target range)

b. significant changes in clinical condition

c. initiation or cessation of pressor or steroid therapy

d. initiation or cessation of renal replacement therapy (dialysis, CVVH, etc.)

e. initiation, cessation, or rate change of nutritional support (TPN, PPN, tube feedings, etc.) initiation, cessation, or rate change of nutritionals (TTPN, PPN, tube feedings, etc.)

\section{CHANGING THE INSULIN INFUSION RATE}

If BG $<50 \mathrm{mg} / \mathrm{dL}:$

D/C INSULIN INFUSION:

Give 1 amp (25 g) D50 IV; recheck blood glucose q 15 minutes.

- When blood glucose $\geq 100 \mathrm{mg} / \mathrm{dL}$, wait 1 hour, recheck BG. If still $\geq 100 \mathrm{mg} / \mathrm{dL}$, restart infusion at $50 \%$ of most recent rate.

\section{If BG 50-69 mg/dL:}

\section{D/C INSULIN INFUSION:}

If symptomatic (or unable to assess), give $1 \mathrm{amp}(25 \mathrm{~g})$ D50 IV; recheck blood glucose q 15 mins.

If asymptomatic, give $1 / 2$ amp (12.5 g) D50 IV; recheck BG q 30 mins.

- When $B G \geq 100 \mathrm{mg} / \mathrm{dl}$, wait 1 hour, recheck BG. If still $\geq 100 \mathrm{mg} / \mathrm{dl}$, restart infusion at $75 \%$ of most recent rate (round off to the nearest 1 unit)

\section{If BG 70-99 mg/dL:}

\section{D/C INSULIN INFUSION FOR 30 mins:}

If repeat $\mathrm{CBG} \geq 100 \mathrm{mg} / \mathrm{dl}$, restart insulin infusion at $75 \%$ of most recent rate (round off to the nearest 1 unit).

If repeat CBG is still $<100 \mathrm{mg} / \mathrm{dl}$, re-chek CBG after 1 hour., resume insulin infusion only at $75 \%$ of most recent rate once repeat $C B G$ is $\geq 100 \mathrm{mg} / \mathrm{dl}$ (round off to the nearest 1 unit).

\section{$\underline{\text { If } B G \geq 100 \text {, go to Step } 2}$}


STEP 2: Determine the RATE OF CHANGE from prior BG level - identifies a CELL in the table. Then move right for the INSTRUCTIONS:

(Note: If the last BG was measured 2-4 hrs. before the current BG, calculate the hourly rate of change.)

\begin{tabular}{|c|c|c|c|c|}
\hline BG $100-139 \mathrm{mg} / \mathrm{dl}$ & BG $140-179$ mg/dl & BG $180-249 \mathrm{mg} / \mathrm{dl}$ & $B G \geq 250 \mathrm{mg} / \mathrm{dl}$ & Instructions \\
\hline & & BG $\uparrow$ by: $>40 \mathrm{mg} / \mathrm{dl} / \mathrm{hr}$ & $B G \square$ & $\uparrow$ Infusion by "2 $2 \Delta$ " \\
\hline & BG $\uparrow$ by: $>20 \mathrm{mg} / \mathrm{dl} / \mathrm{hr}$ & $\begin{array}{l}\text { BG } \uparrow \text { by: } 10-40 \mathrm{mg} / \mathrm{dl} / \mathrm{hr} \\
\text { OR } \\
\text { BG unchanged }\end{array}$ & $\begin{array}{l}\text { BG unchanged } \\
\text { OR } \\
\text { BG } \downarrow \text { by: } 1-40 \mathrm{mg} / \mathrm{dl} / \mathrm{hr}\end{array}$ & $\dagger$ Infusion by " $\Delta$ " \\
\hline$B G \emptyset$ & $\begin{array}{l}\text { BG } \uparrow \text { by: } 10-40 \mathrm{mg} / \mathrm{dl} / \mathrm{hr} \\
\text { OR } \\
\text { BG unchanged } \\
\text { OR } \\
\text { BG } \downarrow \text { by: } 1-20 \mathrm{mg} / \mathrm{dl} / \mathrm{hr}\end{array}$ & BG $\downarrow$ by: $1-40 \mathrm{mg} / \mathrm{dl} / \mathrm{hr}$ & BG $\downarrow$ by: $41-80 \mathrm{mg} / \mathrm{dl} / \mathrm{hr}$ & No infusion change \\
\hline $\begin{array}{l}\text { BG unchanged } \\
\text { OR } \\
\text { BG } \downarrow \text { by: } 1-20 \mathrm{mg} / \mathrm{dl} / \mathrm{hr}\end{array}$ & BG $\downarrow$ by: $21-40 \mathrm{mg} / \mathrm{dl} / \mathrm{hr}$ & BG 1 by: $41-80 \mathrm{mg} / \mathrm{dl} / \mathrm{hr}$ & BG $\perp$ by: $81-120 \mathrm{mg} / \mathrm{dl} / \mathrm{hr}$ & $\downarrow$ Infusion by " $\Delta$ " \\
\hline $\begin{array}{l}\text { BG } \downarrow \text { by: }>20 \mathrm{mg} / \mathrm{dl} / \mathrm{hr} \\
\text { * see below }\end{array}$ & BG $\downarrow$ by: $>40 \mathrm{mg} / \mathrm{dl} / \mathrm{hr}$ & BG $\downarrow$ by: $>80 \mathrm{mg} / \mathrm{dl} / \mathrm{hr}$ & BG $\downarrow$ by: $>120 \mathrm{mg} / \mathrm{dl} / \mathrm{hr}$ & $\begin{array}{l}\text { Hold } \times 30 \text { mins., } \\
\text { then } \square \text { Infusion by "2 } \triangle \text { " }\end{array}$ \\
\hline
\end{tabular}

* D/C INSULIN INFUSION, check CBG after 30 mins, when BG is $\geq 100 \mathrm{mg} / \mathrm{dl}$, restart infusion at 75\% of most recent rate.

CHANGES IN INFUSION RATE (" $\Delta$ ") are determined by the current rate ${ }^{35}$

\begin{tabular}{|l|l|l|}
\hline $\begin{array}{l}\text { Current Rate } \\
\text { (units/hr) }\end{array}$ & $\begin{array}{l}\Delta=\text { rate change } \\
\text { (units/hr) }\end{array}$ & $\begin{array}{l}\mathbf{2}=\mathbf{2} \text { rate change } \\
\text { (units/hr) }\end{array}$ \\
\hline$<3$ & 0.5 & 1 \\
\hline $3-6$ & 1 & 2 \\
\hline $6.5-9.5$ & 1.5 & 3 \\
\hline $10-14.5$ & 2 & 4 \\
\hline $15-19.5$ & 3 & 6 \\
\hline $20-24.5$ & 4 & 8 \\
\hline$\geq 25$ & $\geq 5$ & 10 (consult MD) \\
\hline
\end{tabular}

